\title{
QUALIDADE MICROBIOLÓGICA DE DIFERENTES MARCAS COMERCIAIS DE SUCO FRESCO DE LARANJA INTEGRAL
}

\author{
FERNANDO LEITE HOFFMANN * \\ CRISPIN HUMBERTO GARCIA-CRUZ * \\ TÂNIA MARIA VINTURIM * \\ GEISA SIMPLÍCIO DE OLIVEIRA PAZZOTI *
}

\begin{abstract}
Avaliou-se a qualidade microbiológica de dezenove amostras de diferentes marcas comerciais de suco fresco de laranja integral, consumidas em São José do Rio Preto - SP. Confrontando-se os resultados das análises com os padrões microbiológicos, estabelecidos na legislação federal em vigor, verificou-se que dez $(52,6 \%)$ das dezenove $(100 \%)$ amostras não atenderam a um ou mais padrões, sendo portanto, consideradas inadequadas para consumo.
\end{abstract}

\section{INTRODUÇÃO}

Grande variedade de sucos de frutas, principalmente de laranja (Citrus sinensis), está sendo oferecida ao mercado consumidor brasileiro, entretanto nem todas as marcas refletem e/ou apresentam a qualidade desejada para este produto alimentício.

O suco de frutas cítricas pode ser conceituado como sendo o líquido obtido por expressão ou extração de frutas cítricas, mediante processos tecnológicos adequados (SÃO PAULO, 1978) e, como todo produto alimentício está sujeito a contaminação por diversos tipos de microrganismos.

Os produtos derivados de frutas (sucos, refrescos, néctares, refrigerantes e xaropes), assim como sua principal matéria-prima (as frutas) normalmente apresentam valores de $\mathrm{pH}$ abaixo de 4,0. Desta forma, os problemas de deterioração a que estão sujeitos limitam-se às

Departamento de Engenharia e Tecnologia de Alimentos, Universidade Estadual Paulista, São José do Rio Preto - SP. 
conseqüências das atividades de bolores e leveduras, juntamente com bactérias lácticas e acéticas. Além disso, tais níveis de $\mathrm{pH}$ não são propícios para o desenvolvimento e sobrevivência de bactérias patogênicas (LEITÃO et al., 1977).

Dentre os microrganismos envolvidos na contaminação de produtos muito ácidos, as leveduras são consideradas agentes potenciais de deterioração. Algumas apresentam metabolismo respiratório, oxidando diferentes substratos, particularmente carboidratos. Estas leveduras normalmente não são produtoras de gases e apresentam crescimento restrito às superfícies dos meios (formação de película), não se desenvolvendo em condições de anaerobiose. Sua ocorrência no alimento pode acarretar a elevação do $\mathrm{pH}$, criando condições para o crescimento de outros microrganismos, inclusive patógenos, desde que o pH atinja valores superiores a 4,5. Já outras leveduras são fermentativas, capazes de se desenvolverem em condições anaeróbias, utilizando carboidratos e tendo como principais produtos finais da fermentação o etanol e o $\mathrm{CO}_{2}$.

Os bolores, em sua maioria aeróbios obrigatórios, não são responsáveis por casos de deterioração de alimentos enlatados ou embalados sob vácuo. A exceção é representada pelo Byssochlamys, particularmente $B$. fulva, que é capaz de se desenvolver em meio com baixa tensão de oxigênio. Normalmente pela atividade de bolores não há intensa produção de gases, sendo a deterioração evidenciada principalmente pelo desenvolvimento de colônias com aspecto cotonoso, ou com diferentes colorações advindas da produção de esporos (LEITÃO, 1973, LEITÃO et al., 1977, SOUZA JR. et al., 1974).

Geralmente a presença de bolores e leveduras no produto final é indicativa de condições sanitárias deficientes durante o processamento ou, então, de matérias-primas excessivamente contaminadas.

As enterobactérias, em geral, não se desenvolvem em valores de $\mathrm{pH}$ inferiores a 4,5 e seu tempo de sobrevivência costuma ser variável, apesar de poderem ser isoladas de sucos recém-extraídos (LEITÃO et al., 1977).

Ainda com relação a qualidade microbiológica dos sucos pode-se evidentemente constatar que, quando são produzidos por indústrias de pequeno porte, em instalações precárias e usando embalagens inadequadas, geralmente apresentam problemas sérios de contaminação microbiana, que acarretam elevada porcentagem de rejeição.

Este trabalho teve como objetivo avaliar a qualidade microbiológica de dezenove amostras de diferentes marcas comerciais de suco fresco de laranja integral, consumidas na região de São José do Rio Preto - SP. 


\subsection{OBTENÇÃO DAS AMOSTRAS}

Foram obtidas no comércio varejista da região de São José do Rio Preto (SP) dezenove amostras de suco fresco de laranja integral, de diferentes marcas comerciais, todas dentro do prazo de validade. Estas amostras foram transportadas adequadamente ao laboratório para análise imediata.

\subsection{PREPARO DAS AMOSTRAS}

Pipetou-se assepticamente $10 \mathrm{~mL}$ de amostra, transferiu-se para erlenmeyer contendo $90 \mathrm{~mL}$ de água destilada estéril para posterior homogeneização (diluição $10^{-1}$ ). A partir desta diluição procederam-se as demais diluições decimais seriadas até $10^{-6}$, as quais foram usadas em todas as análises microbiológicas, exceto quando especificado (ICMSF, 1978).

\subsection{CONTAGEM DE BOLORES E LEVEDURAS}

Pipetou-se assepticamente $1 \mathrm{~mL}$ das diluições e distribuiu-se em placas de Petri identificadas. Adicionou-se a cada placa $15 \mathrm{~mL}$ de ágar batata glicose acidificado com ácido tartárico a $10 \%(\mathrm{pH}=4,0)$, seguido de homogeneização. Após solidificação incubou-se a $25{ }^{\circ} \mathrm{C}$, por 5 dias. Calculou-se, de acordo com as diluições, as unidades formadoras de colônias (ICMSF, 1978).

\subsection{DETERMINAÇÃO DO NÚMERO MAIS PROVÁVEL DE COLIFORMES TOTAIS}

Foram inoculadas três séries de três tubos contendo $9 \mathrm{~mL}$ de caldo lauril sulfato triptose com $1 \mathrm{~mL}$ das diluições $10^{-1}, 10^{-2}$ e $10^{-3}$. Homogeneizou-se e incubou-se a $35{ }^{\circ} \mathrm{C}$ durante 48 horas. $\mathrm{O}$ cálculo do número mais provável (NMP) de coliformes totais foi realizado com o auxílio da Tabela de Hoskins (ICMSF, 1978).

\subsection{DETERMINAÇÃO DO NÚMERO MAIS PROVÁVEL DE COLIFORMES FECAIS}

Foi utilizada a técnica dos tubos múltiplos e caldo EC. Após a inoculação os tubos foram incubados a $44,5{ }^{\circ} \mathrm{C}$, por 24 horas (ICMSF, 1978). O cálculo do NMP de coliformes fecais foi efetuado, também, com o auxílio da Tabela de Hoskins. 
Uma alíquota do conteúdo dos tubos contendo caldo EC, que apresentaram turbidez, com ou sem gás no interior do tubo de Durhan, foi semeada em placas de Petri contendo ágar eosina azul de metileno. As colônias suspeitas, de 2 a $3 \mathrm{~mm}$ de diâmetro, que se apresentaram azuis com centro negro e bordas claras à luz transmitida, além de brilho metálico esverdeado à luz refletida foram identificadas com o uso de testes bioquímicos, principalmente o IMVIC (APHA, 1972, ICMSF, 1978).

\subsection{PESQUISA DE Salmonella $s p$}

Em $225 \mathrm{~mL}$ de caldo lactosado e de água peptonada a 1\% foram homogeneizados, respectivamente, $25 \mathrm{~mL}$ de produto. Os dois meios de cultura continham $0,5 \%$ de $\mathrm{Na}_{2} \mathrm{SO}_{3}$ (ICMSF, 1978). Após incubação a $35{ }^{\circ} \mathrm{C}$ por 24 horas, $1 \mathrm{~mL}$ de cada cultivo foi transferido para $10 \mathrm{~mL}$ de caldo tetrationato de Kauffmann e para $10 \mathrm{~mL}$ de caldo selenito cistina e novamente incubados a $35{ }^{\circ} \mathrm{C}$ e $43^{\circ} \mathrm{C}$. Depois de 24 horas, 48 horas e 5 dias foram efetuadas semeaduras, em placas de Petri contendo ágar SS e ágar verde brilhante, sendo as colônias típicas suspeitas submetidas a testes bioquímicos (principalmente inoculação em ágar tríplice açúcar e ferro, em ágar lisina e ferro, teste de urease, degradação do malonato, desaminação da fenilalanina e descarboxilação da lisina) e sorológicos (ICMSF, 1978, SPECK, 1984).

\section{RESULTADOS E DISCUSSÃO}

Os resultados obtidos nas diferentes análises microbiológicas de suco fresco de laranja integral estão demonstrados na Tabela 1.

Independentemente da existência de padrão microbiológico na legislação brasileira em vigor (BRASIL, 1987) para coliformes totais, neste tipo de produto, realizou-se esta determinação para que se tivesse uma idéia de sua carga microbiana e das condições higiênico-sanitárias deste alimento, as quais podem refletir as condições da matéria-prima, do ambiente e do pessoal da produção.

A contagem de bolores e leveduras variou de 5,8 x 10 $10^{1} \mathrm{a} 9,1 \times 10^{5} \mathrm{UFC} / \mathrm{mL}$, a determinação do número mais provável de coliformes totais de $\langle 3 \mathrm{a}\rangle$ $1100 \mathrm{NMP} / \mathrm{mL}$ e a determinação do número mais provável de coliformes fecais de $<3$ a $460 \mathrm{NMP} / \mathrm{mL}$. 


\section{TABELA 1 - RESULTADOS DAS ANÁLISES MICROBIOLÓGICAS - SÃO JOSÉ DO RIO PRETO - 1996}

\begin{tabular}{|c|c|c|c|c|c|}
\hline $\begin{array}{c}\text { Suco fresco } \\
\text { de laranja } \\
\text { integral }\end{array}$ & $\begin{array}{l}\text { Bolores e } \\
\text { leveduras } \\
\text { (UFC/mL) }\end{array}$ & $\begin{array}{l}\text { Coliformes } \\
\text { totais } \\
(\mathrm{NMP} / \mathrm{mL})\end{array}$ & $\begin{array}{l}\text { Coliformes } \\
\text { fecais } \\
(\mathrm{NMP} / \mathrm{mL})\end{array}$ & $\begin{array}{c}\text { Escherichia coli } \\
\text { (confirmativo) }\end{array}$ & $\begin{array}{l}\text { Salmonella sp } \\
\qquad(+/-)\end{array}$ \\
\hline 1 & $1,1 \times 10^{4}$ & $<3$ & $<3$ & - & - \\
\hline 2 & $8,6 \times 10^{3}$ & 4 & 4 & + & - \\
\hline 3 & $2,7 \times 10^{5}$ & 1100 & $<3$ & - & + \\
\hline 4 & $3,7 \times 10^{4}$ & 460 & 11 & + & - \\
\hline 5 & $1,9 \times 10^{5}$ & $<3$ & $<3$ & - & - \\
\hline 6 & $5,8 \times 10^{3}$ & $<3$ & $<3$ & - & - \\
\hline 7 & $5,8 \times 10^{1}$ & $<3$ & $<3$ & - & - \\
\hline 8 & $2,6 \times 10^{3}$ & $<3$ & $<3$ & - & - \\
\hline 9 & $3,4 \times 10^{3}$ & 240 & $<3$ & - & - \\
\hline 10 & $2,4 \times 10^{3}$ & 15 & 7 & + & - \\
\hline 11 & $5,6 \times 10^{4}$ & $>1100$ & $<3$ & - & - \\
\hline 12 & $9,1 \times 10^{5}$ & $<3$ & $<3$ & - & - \\
\hline 13 & $5,6 \times 10^{4}$ & 4 & $<3$ & - & + \\
\hline 14 & $4,9 \times 10^{2}$ & $<3$ & $<3$ & - & - \\
\hline 15 & $3,5 \times 10^{2}$ & $<3$ & $<3$ & - & - \\
\hline 16 & $7,6 \times 10^{2}$ & $<3$ & $<3$ & - & - \\
\hline 17 & $1,2 \times 10^{5}$ & 4 & $<3$ & - & - \\
\hline 18 & $4,0 \times 10^{3}$ & $>1100$ & 460 & + & - \\
\hline 19 & $2,0 \times 10^{3}$ & 240 & 15 & + & - \\
\hline \multirow[t]{3}{*}{ Variação } & $5,8 \times 10^{1}$ & $<3$ & $<3$ & - & - \\
\hline & a & $\mathrm{a}$ & $\mathrm{a}$ & a & $\mathrm{a}$ \\
\hline & $9,1 \times 10^{5}$ & $>1100$ & 460 & + & + \\
\hline $\begin{array}{c}\text { Padrão } \\
\text { Federal } \\
\text { (BRASIL, } \\
\text { 1987) }\end{array}$ & $\begin{array}{l}\text { máximo } \\
10^{4} / \mathrm{mL}\end{array}$ & & $\begin{array}{l}\text { máximo } \\
\text { 10/mL }\end{array}$ & & $\begin{array}{l}\text { ausência em } \\
25 \mathrm{~mL}\end{array}$ \\
\hline \multicolumn{6}{|c|}{$\begin{array}{l}\text { Segundo a legislação federal (BRASIL, 1987), oito }(42,1 \%) \text { das dezenove } \\
\text { amostras de suco fresco de laranja integral analisadas apresentaram-se } \\
\text { em desacordo com o padrão estabelecido (máximo } 10^{4} / \mathrm{mL} \text { ) para bolores e } \\
\text { leveduras. De acordo com a mesma legislação, quatro }(50 \%) \text { destas oito } \\
\text { amostras foram classificadas como "produtos em condiços higiênicas }\end{array}$} \\
\hline
\end{tabular}


insatisfatórias" e as outras quatro como "produtos inaceitáveis para o consumo direto".

Três $(15,8 \%)$ amostras que apresentaram coliformes fecais e confirmaram a presença de Escherichia coli foram classificadas, de acordo com a legislação como "produtos em condições higiênico-sanitárias insatisfatórias" e como "produto inaceitável para o consumo direto". Os resultados do IMVIC para microrganismos nestas três amostras, assim como para outras duas $(10,5 \%)$, que apresentaram também coliformes fecais, confirmando a presença de Escherichia coli, porém atendendo ao padrão da legislação vigente, foram os seguintes: indol (+), vermelho de metila (+), Voges-Proskauer (-) e citrato (-).

Já com respeito a pesquisa de Salmonella $s p$, duas (10,5\%) das dezenove amostras analisadas encontraram-se em desacordo com o padrão (ausência em $25 \mathrm{~mL}$ ) estabelecido na legislação (BRASIL, 1987), sendo classificadas como "produtos potencialmente capazes de causar toxinfecções alimentares" e portanto "produtos impróprios para o consumo". Os microrganismos presentes nestas duas amostras apresentaram também resultados sorológicos condizentes para o gênero Salmonella, assim como previamente nos testes bioquímicos (ágar tríplice açúcar e ferro, ágar lisina e ferro, sendo urease negativos, não metabolizando o malonato, não desaminando a fenilalanina e apresentando resultados positivos para a descarboxilação da lisina).

O presente estudo indica que $52,6 \%$ das amostras analisadas de suco fresco de laranja integral apresentaram-se inadequadas para o consumo, valor este superior ao obtido por CARVALHO et al. (36,6\%) em 1996.

\section{CONCLUSÃO}

Os resultados obtidos evidenciaram que das dezenove amostras analisadas, apenas nove $(47,4 \%)$ encontraram-se em condições higiênicosanitárias adequadas e portanto apropriadas ao consumo. Tal fato é preocupante, uma vez que este tipo de produto é consumido sem nenhum tipo de tratamento térmico, que possa reduzir o número de microrganismos capazes de deteriorar o produto e/ou mesmo ocasionar toxinfecções. 


\begin{abstract}
The microbiological quality of nineteen different commercial brands of integral fresh orange (Citrus sinensis) juice, consumed in São José do Rio Preto, State of São Paulo, Brazil, was evaluated .The results were compared with the microbiological standards established by Federal Legislation. It was verified that ten $(52.6 \%)$ of nineteen $(100 \%)$ analyzed samples did not fulfill one or more of the standards. Therefore, the samples were considered unfit for consumption.
\end{abstract}

\title{
REFERÊNCIAS BIBLIOGRÁFICAS
}

1 AMERICAN PUBLIC HEALTH ASSOCIATION. Métodos recomendados para o exame microbiológico de alimentos. São Paulo : Polígono, 1972. 257 p.

2 BRASIL. Ministério da Saúde. Portaria n. 001 de 28 de janeiro de 1987. Aprova padrões microbiológicos para alimentos. Diário Oficial [da República Federativa do Brasil], Brasília, p. 21982199, 12 de fev. 1987

3 CARVALHO, A.C., JUCÁ, F.L., MOURA, I.P.S., SANTOS, J.G., ARRUDA, L.M., HELENA, S., GIÓIA, T. Análise microbiológica de suco de laranja integral comercializado nas principais avenidas da cidade de Manaus - AM. In: CONGRESSO BRASILEIRO DE CIÊNCIA E TECNOLOGIA DE ALIMENTOS, 15., Poços de Caldas - MG, 1996. Anais... Poços de Caldas, MG, 1996. p. 70.

4 INTERNATIONAL COMMISSION ON MICROBIOLOGICAL SPECIFICATIONS FOR FOODS (ICMSF). Microorganisms in foods: their significance and methods of enumeration. 2. ed. Toronto : University of Toronto Press, 1978. v. 1.

5 LEITÃO, M.F.F. Microbiologia de sucos e produtos ácidos. Boletim do ITAL, Campinas, v. 33, p. 9-42, mar. 1973.

6 LEITÃO, M.F.F., DELAZARI, I., UBOLDI EIROA, M.N., ARIMA, A.K. Avaliação de sucos, refrigerantes, refrescos, néctares e xaropes em face dos padrões microbiológicos brasileiros. Boletim do ITAL, Campinas, v. 49, p. 75-91, jan./fev. 1977.

7 SÃO PAULO (Estado). Decreto n. 12.486 de 20 de outubro de 1978. Aprova normas técnicas especiais relativas a alimentos e bebidas. Diário Oficial, São Paulo, 21 de out. 1978. p. 12 
8 SOUZA JR., A.J., ANGELUCCI, E., LEITÃO, M.F.F., YOKOMIZO, Y., LARA, J.C.M.C. Avaliação química e microbiológica de sucos de frutas brasileiras existentes no mercado. Boletim do ITAL, Campinas, v. 39, p. 43-71, set. 1974.

9 SPECK, M.L. Compendium of methods for the microbiological examination of foods. 2. ed. Washington: APHA, 1984. $914 \mathrm{p}$. 